Maternal mind-mindedness during infancy, general parenting sensitivity and observed child feeding behaviour: a longitudinal study.

\author{
Claire Farrow, Ph.D ${ }^{\mathrm{a}} \&$ Jackie Blissett, $\mathrm{PhD}^{\mathrm{b}}$
}

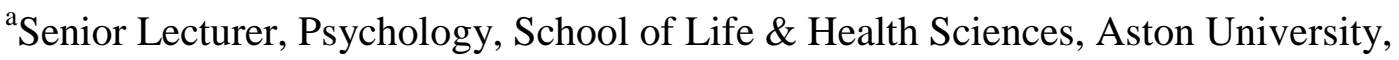
Aston Triangle, Birmingham. B4 7ET.

${ }^{\mathrm{b}}$ Reader, School of Psychology, The University of Birmingham, Edgbaston, Birmingham, B15 2TT, UK.

All correspondence should be addressed to Dr. Claire Farrow, School of Psychology, School of Life \& Health Sciences, Aston University, Aston Triangle, Birmingham, B4 7ET. UK. c.farrow@aston.ac.uk. 01212045384. 


\title{
Maternal mind-mindedness during infancy, general parenting sensitivity and observed child feeding behavior: a longitudinal study.
}

\begin{abstract}
Maternal mind-mindedness, or the tendency to view the child as a mental agent, has been shown to predict sensitive and responsive parenting behavior. As yet the role of mind-mindedness has not been explored in the context of feeding interactions. This study evaluates the relations between maternal mind-mindedness at 6 months of infant age and subsequently observed maternal sensitivity and feeding behaviors with children at age 1 year. Maternal mind-mindedness was greater in mothers who had breast-fed compared to formula-fed. Controlling for breast-feeding, mind-mindedness at 6 months was correlated with observations of more sensitive and positive feeding behaviors at 1 year of age. Mind-mindedness was also associated with greater general maternal sensitivity in play and this general parenting sensitivity mediated the effect of mind-mindedness on more sensitive and positive feeding behaviors. Interventions to promote maternal tendency to consider their child's mental states may encourage more adaptive parental feeding behaviors.
\end{abstract}

Key words: mind-mindedness, child feeding, breast-feeding, sensitive, feeding behavior. 


\section{Introduction}

According to Attachment Theory (Ainsworth, Bell \& Stayton, 1971), sensitive parenting during early childhood is predictive of child security of attachment and superior child outcomes across a range of domains (Brumariu \& Kerns, 2010; Mikulincer \& Shaver, 2012). More recently Elizabeth Meins and colleagues have suggested that parental sensitivity may be preceded by the maternal capacity to read her child at a mental level, appropriately considering her child's thoughts, desires and feelings (Meins, Fernyhough, Fradley, \& Tuckey, 2001; Meins, 2013). Meins et al. (2001) define mind-mindedness as “the mother's proclivity to treat her infant as an individual with a mind, rather than merely as a creature with needs that must be satisfied" (p. 638). Higher levels of this construct indicate an ability to consider the child's thoughts and perspectives, allowing for reasoning about why the child might be behaving in particular ways. This skill renders caregivers more able to use information from their child's behavior to make accurate inference about mental states, and to respond appropriately to these.

There is now a growing body of research linking parental mind-mindedness to more positive parenting behaviors and to superior child linguistic and cognitive development, executive functioning and behavioral outcomes (Meins, Fernyhough, Russell, \& Clark-Carter 1998; Meins, Fernyhough, Arnott, Leekam \& de Rosnay, 2013; Meins, 1998; McMahon \& Meins, 2012; Laranjo, Bernier \& Meins, 2008; Bernier, Carlson \& Whipple, 2010). For example, Meins et al., (2013) found that maternal use of appropriate mind-related comments at 8 months of infant age was associated with better subsequent child performance on a battery of theory of mind tests at 51 months, a relation which was independent of maternal socio-economic status or maternal sensitivity. Importantly, the accuracy of maternal perceptions of 
children's thoughts appear to be critical, and maternal non-attuned mind-related comments at 8 months of infant age were negatively correlated with subsequent child use of internal state language and perspectival symbolic play at 26 months (Meins et al., 2013). Parental mind-mindedness has also been shown to be significantly lower in the parents of children referred to clinical services compared to parents of community samples of children (Walker, Wheatcroft \& Camick, 2012), with mind-mindedness also being related to parenting stress in clinical samples, and to children's emotional and behavioral difficulties in community samples (Walker et al., 2012).

The effects of mind-mindedness on parenting are likely part of a wider network of processes whereby attachment security, sensitivity and mind-mindedness interact and impact upon each other throughout the course of parenting. Researchers have begun to attempt to establish how these inter-related networks may evolve and in turn influence each other. The positive impacts of mind-mindedness on sensitivity and attachment have consistently been demonstrated across early childhood. For example, in a large, socially diverse sample, higher scores for maternal appropriate mindrelated comments at 8 months of infant age have been show to predict child attachment security at 15 months of age, independently of maternal sensitivity (Meins et al., 2012). In attempting to explain the intergenerational transmission of attachment, Bernier and Dozier (2003) found that maternal mind-mindedness significantly mediated the relation between adult state of mind with respect to attachment and subsequent infant attachment security. Moreover, Laranjo et al., (2008) have suggested that mind-mindedness is a pre-requisite to maternal sensitivity, with sensitivity mediating the relation between mind-mindedness and attachment security over time. 
Despite the wealth of research demonstrating that mind-mindedness predicts more adaptive parenting behavior and child outcomes in areas of cognition, linguistics and play (Meins et al., 1998; Meins et al., 2013; Meins, 1998; McMahon \& Meins, 2012; Laranjo et al., 2008; Bernier et al., 2010), no research to date has explored how maternal mind-mindedness may be related to parental feeding and child eating behavior. This is perhaps surprising given that early infant feeding, both milk feeding and solid feeding, occupies a large part of parenting time and is said to be one of the main areas of concern for parents of young children (Mitchell, Farrow, Haycraft \& Meyer, 2013). Children's signals around feeding can be difficult to read and interpret given their limitations with verbal language. The ability to accurately infer children's mental states is likely to help mothers in this potentially stressful time and may play an important role in determining milk-feeding style (i.e. breast or formula-feeding) as well as sensitivity and interactional behavior when feeding solid foods.

In terms of milk feeding, the beneficial effects of breast-feeding for mothers and infants are widely documented, yet prevalence rates for breast-feeding remain far below recommendations in the U.K. (Bartington, Griffiths, Tate, Dezateux, \& The Millennium Cohort Study Child Health Group, 2006). Previous research has demonstrated elevated levels of maternal sensitivity during early infancy amongst women who breast-fed compared to those who formula-fed (Britton, Britton \& Gronwaldt, 2006), moreover, intention to breast-feed prenatally appears to be a marker for later parenting sensitivity (Britton et al., 2006). The relations between breast-feeding and parenting behavior are complex and likely bi-directional, but physiologically, breast-feeding women have been demonstrated to show elevated responses to infant crying cues in brain regions which are associated with maternalinfant empathy and bonding (Kim et al., 2011). This may in turn impact maternal 
ability to read the child as a mental agent. This research aims to extend these findings by evaluating whether there are differences between women who breast-feed compared to those who formula-feed in terms of both general parenting sensitivity as well as in maternal ability to attribute mental intent to her child. We will also explore whether there is a cumulative effect of breastfeeding and whether the duration of breastfeeding is related to these constructs.

With regard to feeding children solid foods, a wealth of research has demonstrated that how parents feed children and interact around food can have a significant impact on food preferences, eating behavior and weight (Mitchell et al., 2013). In their early observations, Ainsworth and Bell (1969) describe how mothers who are sensitive and responsive during early infant feeding interactions, tending to "be able to see things from the baby's point of view" (p.156) are more likely to have infants who cry less and are more securely attached at 1 year. More recent research has supported this and shown that caregivers' who respond in more sensitive ways to child feeding signals, not pressuring children to eat when they do not want to (Galloway, Fiorito, Francis \& Birch, 2006), and not overly restricting access to food when children are hungry (Jansen, Mulkens, Emond \& Jansen, 2008) are more likely to have children who can respond appropriately to their own signals of hunger and satiety, being less likely to be fussy eaters or to be overweight (Powell, Farrow \& Meyer, 2011). General parenting styles have been shown to inform these specific feeding behaviors (Blissett, 2011), and mind-mindedness has been linked with general parenting behaviors in other contexts (e.g. Meins et al., 2012). What is as yet unclear is whether maternal mind-mindedness may also impact upon more positive and sensitive behavior in the context of feeding, and whether this impact may be accounted for in part by elevated levels of general parenting sensitivity. 
This study aims to bring together research on mind-mindedness with that on child feeding by exploring whether maternal mind-mindedness predicts more sensitive and positive parental feeding behavior, and whether this proposed impact is mediated by greater general maternal sensitivity. In order to explore how mindmindedness might predict the development of maternal feeding behavior over time, this research utilizes a longitudinal design; evaluating maternal mind-mindedness at 6 months of age when infants are being introduced to solid foods and examining its relations with subsequent parental feeding behaviors at age 1 year. In order to avoid self-report bias, this study uses observations of maternal feeding behaviors and interactions during play. To minimize the confounding impact of shared-method variance, an interview-based measure of maternal mind-mindedness is employed (the “describe your child" interview; Meins et al., 1998) as opposed to an observational measure. This interview-based measure has not previously been described with mothers of children during the first year of life, the data will therefore illustrate whether this interview-based measure can capture mind-mindedness at this early stage of development before children learn to speak.

It is hypothesized that mothers who breast-feed will demonstrate higher levels of mind-mindedness than those who formula-feed their infants, and that the duration of breast-feeding will be positively associated with greater mind-mindedness. It is hypothesized that mothers with higher levels of mind-mindedness at 6 months of age will use more sensitive, positive and less negative behaviors and vocalizations during mealtime interactions with their children at 1 year. It is also hypothesized that general parenting sensitivity will mediate the impact of maternal mind-mindedness on these feeding behaviors over time. 


\section{Method}

\section{Participants}

Seventy four mothers of 35 boys and 39 girls gave informed consent to take part in this longitudinal study when their children were aged 6 months and 1 year. Women were from a wide range of occupational background with a mean occupational level of 4 on the National Statistics Socio-economic Classification, corresponding to administrative and secretarial occupations (Office of National Statistics, 2010). The mean age of the mothers was 32 years $(\mathrm{SD}=5.21)$. Sixty women had breast-fed and 14 had not breast-fed their children, the mean length of breast-feeding for the women who had breast-fed was 27.13 weeks $(\mathrm{SD}=17.76$, range $=1-55)$. Women were recruited from antenatal clinics as part of a larger longitudinal study initiated during pregnancy, details of which are published elsewhere (Farrow \& Blissett, 2006; Farrow \& Blissett, 2007). Ethical approval for this research was obtained from South Birmingham Research Ethics Committee.

\section{Measures}

Women with their children were visited in their homes when their children were approximately 6 months and 1 year of age. Women provided background information about their age, their occupation (or occupation prior to motherhood), their child's gender, whether they had breast-fed, and if so for how long. All children were weighed and scores were converted to standard deviation scores to consider exact child age and gender (Child Growth Foundation, 1996). During these home visits the following measures were also completed:

\section{Mind-mindedness}


Mothers were interviewed using a single item question at 6 months of age to assess mind-mindedness: 'Can you describe [child] for me?' Mothers were instructed to talk about anything they wanted in relation to the question and there were no right or wrong answers. Maternal responses to this question were recorded using a digital voice recorder and were transcribed verbatim. This method has been widely used to assess mind-mindedness (Meins \& Fernyhough, 1999; Meins et al., 1998; McMahon \& Meins 2012) and each characteristic described in the response is coded as mental (e.g. "she is thoughtful", "she lets you know if she wants something"), behavioral (e.g. "she is very shy"), physical (e.g. "she is small for her age") or general (comments not fitting other categories). In order to control for verbosity, mindmindedness is coded according to the proportion of mental attributes described in relation to the total number of attributes, with higher scores indicating greater mindmindedness. Previous research using this interview measure has found that mindmindedness at age 3 is related to security of attachment during infancy (Meins et al., 1998), and also to child performance on false belief and emotion tests at age 5 (Meins \& Fernyhough, 1999). Nineteen percent of the interviews were coded by a second trained observer to ascertain inter-rater reliability, this yielded an intraclass correlation coefficient of $.70(\mathrm{p}<.05)$. Coders were trained to assess comments by the research supervisor and with reference to the latest coding manual for assessing mindmindedness (Meins \& Fernyhough, 2010).

\section{Parental feeding practices}

Mothers were observed during a natural feeding observation with their infants in the family home at approximately 1 year of age. Feeding interactions were recorded using a video camera placed in an unobtrusive position to facilitate normal feeding 
behavior. Recordings were coded to assess a range of maternal behaviors using the Feeding Interaction Scale (FIS: Wolke, Sumner, McDermott \& Skuse, 1987).

Maternal behavior assessed by the FIS includes the following: frequency of verbal involvement (amount the mother talks to the child throughout the meal); extent of verbal control (amount the mother directs or prohibits the child verbally during the meal); non-verbal controlling behavior (controlling behavior includes force feeding or distracting the child to inert food into mouth); physical contact during the mealtime (how much bodily contact and touching the mother initiates); the frequency of expressed positive and negative emotion (i.e. endearment and affection compared to irritation and negativity); appropriateness of maternal behavior (i.e. is feeding is functional, flexible and pleasurable for the child); and sensitivity of maternal behavior (rated according to various markers including positioning of child, distance from child, behavior during meal, comments and timing of feeding). Behaviors are coded along these 8 different subscales which are each rated on ordinal scales. Higher scores for all constructs indicate more positive maternal mealtime behavior because scores for negative subscales (verbal control, non-verbal controlling behavior, negative emotion) are reverse scored. These 8 behaviors measured on the FIS can be grouped into 3 aggregate factors: factor 1 sensitivity (including non-verbal controlling behavior, sensitivity and physical contact, $\alpha=.64$ ); factor 2 positive vocalization (including verbal involvement, positive emotion and appropriateness, $\alpha=.79$ ); and factor 3 negative control (including verbal control and negative emotion, $\alpha=.75$ ). The FIS has previously been used to assess maternal-child feeding interactions and has good validity in its use to diagnose feeding problems in children (Lindberg, Bohlin, Hagekull \& Palmerus 1996; Skuse, Wolke \& Reilly, 1992; Wolke \& Skuse, 1992; Farrow \& Blissett, 2006). In order to ascertain inter-rater reliability, $19 \%$ of the 
observations were coded by a second trained observer, the mean intraclass correlation coefficient across the 2 coders was .72 (all p's $<.05$; specific coefficients are: .66 verbal involvement; .78 verbal control; .69 non-verbal controlling behavior; .83 physical contact; .65 positive emotion; .60 negative emotion; .82 appropriate behavior; .67 feeding sensitivity).

\section{Parental sensitivity during play}

Mothers were also observed during general play at this 1 year visit, in a natural setting where the mother and child were comfortable within the family home. Mothers were provided with a range of toys and were asked to play with their infants as they normally would for 10 minutes. Observations were recorded and maternal sensitivity during the play interaction was coded according to Ainsworth, Bell \& Stayton's (1974) 9-point sensitivity scale, which assesses maternal sensitivity ranging from highly sensitive to highly insensitive, with higher scores indicating greater sensitivity. This scale is widely used by researchers to obtain an overall score of maternal sensitivity during play (e.g. Lindberg et al., 1996; Meins et al., 2001). Observers were trained independently to use the coding scheme by the research supervisor who has expertise in coding parent-child interaction behavior. Nineteen percent of the videos were coded by a second trained observer and the intraclass correlation coefficient was .79 $(\mathrm{p}<.01)$.

\section{Results}

\section{Analysis strategy}

Following descriptive statistics, the data were screened to examine the impact of various potentially confounding demographic variables. Independent sample t-tests 
were used to compare women who had breast-fed to those who had formula-fed on mind-mindedness, parenting sensitivity and feeding behavior. Pearson's correlations were used to examine associations between length of breast-feeding with these variables. Correlations (partial correlations controlling for breast-feeding occurrence and duration, and bivariate correlations) were then used to examine the hypothesized relations between maternal mind-mindedness at 6 months of age with maternal general sensitivity and feeding behavior at 1 year. Finally bootstrapping mediation analyses (Preacher \& Hayes, 2008) were used to examine the proposed relations between maternal mind-mindedness and feeding behavior, with general parenting sensitivity as the mediator.

\section{Screening for confounding variables}

In order to control for potentially confounding effects of demographic variables, the data were screened to explore whether maternal age, occupation, child gender or weight were related to maternal mind-mindedness. Independent sample ttests indicated that there were no significant differences in levels of mind-mindedness recorded for mothers of male compared to female children $[\mathrm{t}(72)=.60, \mathrm{p}=.55$; male $\mathrm{M}$ $=.31(\mathrm{SD}=.14)$, female $\mathrm{M}=.28(\mathrm{SD}=.15)]$, and Pearson's correlations indicated that maternal age $(\mathrm{r}=.10, \mathrm{p}=.38)$, occupational code $(\mathrm{r}=-.17, \mathrm{p}=.15)$, and child weight $\mathrm{z}$-score at 6 months $(\mathrm{r}=.04, \mathrm{p}=.68)$ were unrelated to mind-mindedness. Therefore, the sample was collapsed and these variables were not explored further.

\section{Descriptive statistics}

Mean and standard deviation scores for maternal mind-mindedness and maternal feeding behavior are presented in Table 1. Mean scores for all measures are 
similar to other published data (Lindberg et al., 1996), with the exception of mindmindedness. The mean scores for the proportion of mind-minded comments was .29 which is lower than the previously reported mean proportions of .44 (Meins et al., 2003) and .36 (average across groups in both studies: McMahon \& Meins, 2012; Meins et al., 1998) for mothers of 3 and 4 year old children. This suggests that mothers are able to make mental descriptions of their children during the first year of life but that these descriptions are proportionately less than those given for older children. The fact that these infants are unable to speak will mean that mothers have to infer thoughts and desires as children cannot explicitly state them, and this may lead to lower maternal reference to mind related attributes during interview.

Relations between maternal breast-feeding with mind-mindedness, general sensitivity and solid feeding behavior

Independent sample t-tests indicated that there were significant differences between women who breast-fed compared to those who did not in terms of mindmindedness at 6 months and observed general sensitivity at 1 year (see Table 2). Moreover, Pearson's correlations indicated that the length of breast-feeding in weeks was significantly related to observed feeding sensitivity and positive vocalization, as well as to observed general sensitivity at 1 year. We therefore controlled for maternal breast-feeding status and breast-feeding duration in subsequent analyses.

Mind-mindedness as a pivotal state of mind and its relation to aspects of maternal feeding behavior and sensitivity

As indicated in Table 3, mothers who used more mind-related comments in interviews about their infants at 6 months of age were observed to be more sensitive 
during play observations and also more sensitive and used more positive vocalization whilst feeding [Table 3 about here]. General maternal sensitivity during play was also significantly correlated with observations of greater feeding sensitivity, positive vocalization and less negative control during feeding interactions.

\section{Does general maternal sensitivity mediate the relations between mind-mindedness with sensitive and positive feeding behavior?}

Bootstrapping mediation (Preacher \& Hayes, 2008) was used to assess whether general maternal sensitivity at 1 year mediated the relations between maternal mind-mindedness at 6 months with sensitive feeding behavior and positive vocalization during feeding at 1 year.

For feeding sensitivity, there was a significant effect of maternal mindmindedness at 6 months on feeding sensitivity at 1 year $(b=.07, t=2.53, p=.01)$ and on the mediator, observed general sensitivity in play $(b=.03, t=3.28, p=.00)$. There was also a significant relation between general sensitivity and feeding sensitivity at 1 year $(\mathrm{b}=1.50, \mathrm{t}=5.34, \mathrm{p}=.00)$. When mind-mindedness at 6 months and sensitivity were entered into the equation simultaneously, the direct effect of mind-mindedness on feeding sensitivity at 1 year was non- significant $(b=.02, t=.85, p=.40)$. This indirect effect was significant as the bias corrected confidence interval did not include zero $(95 \% \mathrm{CI} .02, .09)$. Thus, general maternal sensitivity significantly mediated the effects of maternal mind-mindedness on observed feeding sensitivity.

For positive vocalization during feeding, there was a significant effect of maternal mind-mindedness at 6 months on positive vocalization at 1 year $(\mathrm{b}=.06, \mathrm{t}=$ $2.66, \mathrm{p}=.01)$ and on the mediator, observed general sensitivity in play $(\mathrm{b}=.03, \mathrm{t}=$ $3.28, \mathrm{p}=.00)$. There was also a significant relation between general sensitivity and 
positive vocalization at 1 year $(\mathrm{b}=1.40, \mathrm{t}=5.45, \mathrm{p}=.00)$. When mind-mindedness at 6 months and sensitivity were entered into the equation simultaneously, the direct effect of mind-mindedness on positive vocalization at 1 year was non-significant $(b=$ $.02, \mathrm{t}=.97, \mathrm{p}=.33$ ). This indirect effect was significant as the bias corrected confidence interval did not include zero (95\% CI .01, .08). Thus, general maternal sensitivity significantly mediated the effects of maternal mind-mindedness on observed positive vocalization during feeding.

\section{Discussion}

The results indicate that maternal mind-mindedness at 6 months of infant age, or the tendency to describe her infant with intentions, thoughts and feelings, is directly predictive of more positive and sensitive maternal behaviors during feeding with the child at one year, relations accounted for by mind-minded mothers being more sensitive in general parenting. The results also indicate that mind-mindedness is higher in women who breast-feed their infants, but irrespective of breast-feeding status, the effect of mind-mindedness on subsequent feeding behavior was evident.

By the very nature of its definition, mothers who are more mind-minded are more likely to consider their child's thoughts and feelings and this tendency may directly foster the use of more involved and responsive parenting at mealtimes, focused on the child's pleasure in the experience. Supporting observational findings of Laranjo et al. (2008), the results suggest that mind-mindedness is a pre-requisite to maternal sensitivity. Laranjo et al. (2008) explain that in order to be able to respond sensitively and appropriately to child signals, mothers must be able to attribute intent to the child's signals and to interpret them correctly. The results of this research may suggest that mothers who are less able to consider their child's emotional responses 
may view mealtimes as more functional than social in nature, and be more focused on the act of feeding and ensuring that the child eats how or what the mother desires. Such a focus may detract from expressing positive vocalizations and sensitivity around feeding and may lead to a more insensitive feeding style, not attuned to the child's emotional needs. These findings support other research which has shown that mind-mindedness is predictive of more sensitive and responsive caregiving behavior (Meins et al., 2001; Laranjo et al., 2008; Degotardi \& Sweller, 2012), but extend our theoretical understanding of the effects of mind-mindedness by illustrating the positive consequences of this construct for early child feeding.

The results also demonstrate that general maternal sensitivity, as assessed during play, mediates the relation between previous mind-mindedness and subsequent sensitive and positive feeding behavior. These findings begins to shed light on the temporal precedence of these processes and suggests that elevated parenting sensitivity may be the feature of mind-mindedness that creates a more appropriate and responsive style of feeding.

The finding that mothers who had breast-fed their infants were more likely to attribute mental states to the infant at 6 months suggests that the experience of breastfeeding may promote maternal thoughts about her infant's mental states, or that the tendency to be mind-minded may encourage breast-feeding. Breast-feeding has previously been shown to promote less controlling and more responsive interactions with the child (Farrow \& Blissett, 2006), with previous authors suggesting that breastfeeding mothers learn to listen and respond more appropriately to their child's cues (Fisher, Birch, Smiciklas-Wright, \& Picciano, 2000). This ability may translate from the act of feeding into a more general view of the child and his or her intentions. Alternatively, given that mind-mindedness is believed to be present before birth 
(Arnott \& Meins, 2008), it therefore may precede the decision to breast-feed. Indeed, attitudes towards breast-feeding and the intention to control infant feeding are characteristics which are present and measurable prenatally, and predict the subsequent duration of breast-feeding (Brown \& Lee, 2010). It is possible that the relations between mind-mindedness with sensitive and positive maternal feeding are enhanced in some way by the experience of breast-feeding. Irrespective of this, the data indicate that whether a woman breast-feeds or not, the ability to see her child in mental terms is predictive of more appropriate and responsive feeding behavior at 1 year of age.

The findings of this research are unique in that they are the first to explore the relations between mind-mindedness and early infant feeding. Moreover this is the first study to use the 'describe your child' interview of mind-mindedness during the first year of life. Although the mean score on this measure was lower than previously published means with older children (e.g., Meins et al., 2003), mothers were able to use this interview to make mental attributions about their child. It is important to note however that by using this interview method we have no account of whether the mind related comments were accurate or not. Recent research indicates that the accuracy of mind-related comments is important and than non-attuned comments may predict child behavioral outcomes differently to appropriate mind-related comments (Meins et al., 2013; Meins, 2013). In addition, the nature of maternal interpretation of the child's mind is important, and whilst maternal interpretation of the child's intent may be accurate it may not necessarily always be accompanied by a positive emotional tone. For example, in a study with mothers with severe mental illness, Pawlby et al., (2010) describe how one mother inferred accurate interpretation of the child's mind but was irritated by this (the child was fascinated with a strap and therefore ignoring 
the mother's attempts to engage). Similarly, in this study some comments made by mothers during the interview may have indicated a hostile attribution bias (e.g. "he is stubborn"), and future research is needed to appreciate how reference to different aspects of child intent, and the emotional response to these, may impact differently on responsiveness in terms of feeding or other aspects of parenting.

The use of a longitudinal design and observational measures are strengths of this study, however, the relatively homogenous and small sample indicate that the results require replication. This study relies on one observation of a feeding interaction at one year; given that mealtimes can be variable for young children (Parkinson \& Drewett, 2001), the design could be strengthened by drawing on and merging data from repeated and separate observations. Further research would benefit from evaluating the impact of maternal mind-mindedness on feeding interactions with older children who are more independent in their eating behaviors, and those with clinically significant eating problems. Many interventions exist aimed at improving child feeding and eating behavior by giving advice about what to eat and how to feed children in ways that may foster healthy acceptance of foods (Mitchell et al., 2013). The findings of this research indicate that, in addition to training about what and how to feed children, interventions should also focus on promoting caregiver attention to the child's autonomous thoughts, intentions and feelings around mealtimes. By elevating mind-mindedness this could help to foster more sensitive and positive feeding behavior, which may ultimately benefit child health and well-being. 


\section{References}

Ainsworth, M. D. S., \& Bell, S. M. (1969). Some contemporary patterns of motherinfant interaction in the feeding situation. In A. Ambrose (Hrsg.). Stimulation in early infancy (pp133-170). London: Academic Press.

Ainsworth, M. D. S., Bell, S. M., \& Stayton, D. J. (1971). Individual differences in Strange Situation behaviour of one year olds. In H. R. Schaffer (Ed.), The origins of human social relationships (pp. 15-71). New York: Academic Press.

Ainsworth, M., Bell, S., \& Stayton, D. (1974). Infant-mother attachment and social development: 'Socialisation' as a product of reciprocal responsiveness to signals. In M. P. Richards (Ed.), The introduction of the child into a social world (pp. 99-135). London: Cambridge University Press.

Arnott, B., \& Meins, E. (2008). Continuity in mind-mindedness from pregnancy to the first year of life. Infant Behavior \& Development, 31, 647-654. doi:

10.1016/j.infbeh.2008.07.001

Bartington, S., Griffiths, L. J., Tate, A. R., Dezateux, C., \& The Millenium Cohort Study Child Health Group. (2006). Are breastfeeding rates higher among mothers delivering in Baby Friendly accredited maternity units in the UK? Int. J. Epidemiol., 35, 1178-1186.

Bernier, A., Carlson, S. M., \& Whipple, N. (2010). From external regulation to selfregulation: early parenting precursors of young children's executive functioning. Child Development, 81, 326-39. doi: 10.1111/j.1467-8624.2009.01397.x Bernier, A., \& Dozier M. (2003). Bridging the attachment transmission gap: The role of maternal mind-mindedness. International Journal of Behavioral Development, 27, 355-365. doi: 10.1080/01650250244000399 
Blissett, J. (2011). Relationships between parenting style, feeding style and feeding practices and fruit and vegetable consumption in early childhood. Appetite, 57, 826831.doi:10.1016/j.appet.2011.05.318

Britton, J. R., Britton, H. L., \& Gronwaldt, V. (2006). Breastfeeding, Sensitivity, and Attachment. Pediatrics, 118, 1436-e1443. doi: 10.1542/peds.2005-2916

Brown, A. E., \& Lee, M. D. (2010). Intended maternal control over milk feeding is measurable prenatally. Differences between mothers who plan to breast or formula feed. Appetite, 55, 166-167. doi:10.1016/j.appet.2010.05.056

Brumariu, L. E., \& Kerns, K. A. (2010). Parent-child attachment and internalizing symptoms in childhood and adolescence: a review of empirical findings and future directions. Dev Psychopathol, 22, 177-203. doi: 10.1017/S0954579409990344 Child Growth Foundation. (1996). Cross sectional stature and weight reference curves for the UK. London: Child Growth Foundation.

Degotardi, S., \& Sweller, N. (2012). Mind-mindedness in infant child-care: Associations with early childhood practitioner sensitivity and stimulation. Early Childhood Research Quarterly, 27, 253-265 doi:10.1016/j.ecresq.2011.09.002 Farrow, C., \& Blissett, J. (2006). Breast-feeding, maternal feeding practices and mealtime negativity at one year. Appetite, 46, 4-56. doi:10.1016/j.appet.2005.10.005 Farrow, C., \& Blissett, J. (2007). The development of maternal self-esteem. Infant Mental Health Journal, 28, 517-535. doi: 10.1002/imhj.20151

Fisher, J. O., Birch, L. L. Smiciklas-Wright, H., \& Picciano, M. F. (2000). Breastfeeding through the first year predicts maternal control in feeding and subsequent toddler energy intakes. Journal of the American Dietetic Association, 100, 641-646. doi: $10.1016 / \mathrm{S} 0002-8223(00) 00190-5$

Galloway, A. T., Fiorito, L. M., Francis, L. A., \& Birch, L. L. (2006). 'Finish your 
soup': Counterproductive effects of pressuring children to eat on intake and affect. Appetite, 46, 318-323. doi: 10.1016/j.appet.2006.01.019

Hagekull, B., Bohlin, G., \& Rydell, A. M. (1997). Maternal sensitivity infant temperament and the development of early feeding problems. Infant Mental Health Journal, 18, 92-106. doi: 10.1002/(SICI)1097-0355

Jansen, E., Mulkens, S., Emond, Y., \& Jansen, A. (2008). From the Garden of Eden to the land of plenty: Restriction of fruit and sweets intake leads to increased fruit and sweets consumption in children. Appetite, 51, 570-575. doi:

10.1016/j.appet.2008.04.012

Kim, P., Feldman, R., Mayes, L .C., Eicher, V., Thompson, N., Leckman, J. F., \& Swain, J. E. (2011). Breastfeeding, brain activation to own infant cry, and maternal sensitivity. Journal of Child Psychology and Psychiatry, 52, 907-15.

doi: 10.1111/j.1469-7610.2011.02406.x

Laranjo, J., Bernier, A., \& Meins, E. (2008). Associations between maternal mindmindedness and infant attachment security: Investigating the mediating role of maternal sensitivity. Infant Behavior and Development, 31, 688-695. doi:

10.1016/j.infbeh.2008.04.008

Lindberg, L., Bohlin, G., Hagekull, B., \& Palmerus, K. (1996). Interactions between mothers and infants showing food refusal. Infant Mental Health Journal, 17, 334 347.doi: 10.1002/(SICI)1097-0355(199624)

McMahon, C. A. \& Meins, E. (2012). Mind-mindedness, parenting stress, and emotional availability in mothers of preschoolers. Early Childhood Research Quarterly, 27, 245. doi:10.1016/j.ecresq.2011.08.002 
Meins, E. (1998). The effects of security of attachment and maternal attribution of meaning on children's linguistic acquisitional style. Infant Behaviour and Development, 21, 237-252.

Meins, E. (2013). Sensitive attunement to infants' internal states: operationalizing the construct of mind-mindedness. Attachment and Human Development, 15, 524-544. doi:10.1080/14616734.2013.830388

Meins, E., \& Fernyhough, C. (1999). Linguistic Acquisitional Style and Mentalising Development: The Role of Maternal mind-mindedness. Cognitive Development, 14, 363-380. doi: 10.1016/S0885-2014(99)00010-6

Meins, E., \& Fernyhough, C. (2010). Mind-mindedness coding manual, Version 2.0. Unpublished manuscript. Durham University, Durham, UK. Available from http://www.academia.edu/1300377/Mind-mindedness_coding_manual Meins, E., Fernyhough, C., Arnott, B., Leekam, S.R., \& de Rosnay, M. (2013). MindMindedness and Theory of Mind: Mediating Roles of Language and Perspectival Symbolic Play. Child Development, 84, 1777-1790. doi: 10.1111/cdev.12061 Meins, E., Fernyhough, C., Fradley, E. \& Tuckey, M. (2001). Rethinking maternal sensitivity: Mothers' comments on infants' mental processes predict security of attachment at 12 months. Journal of Child Psychology and Psychiatry, 42, 637-648 Meins, E., Fernyhough, C., de Rosnay, M., Arnott, B., Leekam, S. R., \& Turner, M. (2012). Mind-mindedness as a multidimensional construct: Appropriate and nonattuned mind-related comments independently predict infant-mother attachment in a socially diverse sample. Infancy, 17, 393-415. doi: 10.1111/j.15327078.2011.00087.x 
Meins, E., Fernyhough, C., Russell, J. \& Clark-Carter, D. (1998). Security of attachment as a predictor of symbolic and mentalising abilities: A longitudinal study. Social Development, 7, 1-24. doi: 10.1111/1467-9507.00047

Meins, E., Fernyhough, C., Wainwright, R., Clark-Carter, D., Das Gupta, M., Fradley, E. \& Tuckey, M. (2003). Pathways to understanding mind: Construct validity and predictive validity of maternal mind-mindedness. Child Development, 74, 1194-1211. doi: 10.1111/1467-8624.00601

Mikulincer, M. \& Shaver, P. R. (2012). An attachment perspective on psychopathology. World Psychiatry, 11, 11-5.

Mitchell, G., Farrow, C., Haycraft, E., \& Meyer, C. (2013). Parental influences on children's eating behaviour and characteristics of successful parent-focussed interventions. Appetite, 60, 85-94. doi: 10.1016/j.appet.2012.09.014

Office of National Statistics (2010). Standard Occupational Classification 2010. London: The Stationary Office.

Parkinson, K. N., \& Drewett, R. F .J. (2001). Feeding behaviour in the weaning period. Child Psychol Psychiatry, 42, 971-8. doi: 10.1111/1469-7610.00793 Pawlby, S., Fernyhough, C., Meins, E., Pariante, C.M., Senevirante, G., \& Bentall, R.P. (2010). Mind-mindedness and maternal responsiveness in infant-mother interactions in mothers with severe mental illness, Psychological Medicine, 40, 18611869. doi: $10.1017 / \mathrm{S} 0033291709992340$

Powell, F. C., Farrow, C., \& Meyer, C. (2011). Food avoidance in children. The influence of maternal feeding practices and behaviours. Appetite, 57, 683-692. doi: 10.1016/j.appet.2011.08.011

Preacher, K. J., \& Hayes, A. F. (2008). Asymptotic and resampling strategies for 
assessing and comparing indirect effects in multiple mediator models. Behavior Research Methods, 40, 879-891. doi:10.3758/BRM.40.3.879

Skuse, D., Wolke, D., \& Reilly, S. (1992). Failure to thrive: clinical and developmental aspects. In H. Remschmidt \& M. Schmidt (Eds.), Child and Youth Psychiatry: European Perspectives, volume 2, Developmental Psychopathology (pp. 46-69). Hans Huber Stuttgart: Germany.

Walker, T.M., Wheatcroft, R., \& Camic, P.M. (2012). Mind-mindedness in parents of pre-schoolers: a comparison between clinical and community samples. Clin Child Psychol Psychiatry, 17, 318-35. doi: 10.1177/1359104511409142

Wolke, D., \& Skuse, D. (1992). The management of infant feeding problems. In P. Cooper \& A. Stein (Eds.), Feeding problems and eating disorders in children and adolescents (pp. 27-59). Chur, Switzerland: Harwood.

Wolke, D., Sumner, M., McDermott, Y., \& Skuse, D. (1987). The Feeding Interaction Scale. Unpublished Work. Also available in: Skuse, D., Wolke, D., \& Reilly, S. (1992). Failure to thrive. Clinical and developmental aspects. In H. Remschmidt \& M. Schmidt (Eds.), Child and psychiatry. European perspectives. Vol.II: developmental psychopathology (pp. 46-71). Stuttgart: Hans Huber. 
Table 1

Mean scores for mind-mindedness, observed general sensitivity and feeding behavior

\begin{tabular}{lll}
\hline & Mean & SD \\
\hline Mind-mindedness at 6 months & .29 & .14 \\
\hline Observed maternal sensitivity in play at & 6.92 & 1.26 \\
1 year & & \\
\end{tabular}

Observations of maternal feeding

behaviors at 1 year:

Sensitivity

Positive vocalization

Negative control
19.20

3.43

12.35

3.17

11.77 
Table 2

Relations between breast-feeding status and duration with mind-mindedness, observed general sensitivity and feeding behavior at 1 year

\begin{tabular}{|c|c|c|c|c|}
\hline & t-test & Mean (SD) & Mean (SD) & Correlation $^{\mathrm{a}}$ \\
\hline & $t(d f)$ & Breast-fed & Not breast-fed & $\mathrm{r}$ \\
\hline $\begin{array}{l}\text { Mind-mindedness } \\
\text { at } 6 \text { months }\end{array}$ & $2.33(72), \mathrm{p}=.02 *$ & $.31(.14)$ & $.22(.16)$ & $.22, p=.06$ \\
\hline $\begin{array}{l}\text { Feeding sensitivity } \\
1 \text { year }\end{array}$ & $1.56(72), p=.12$ & $19.5(3.43)$ & $17.93(3.25)$ & $.25, \mathrm{p}=.04^{*}$ \\
\hline $\begin{array}{l}\text { Positive feeding } \\
\text { vocalization at } 1 \\
\text { year }\end{array}$ & $1.50(72), p=.14$ & $12.62(3.19)$ & $11.21(2.89)$ & $.31, \mathrm{p}=.01 *$ \\
\hline $\begin{array}{l}\text { Feeding negative } \\
\text { control at } 1 \text { year }\end{array}$ & $1.89(72), \mathrm{p}=.06$ & $12.02(2.30)$ & $10.71(2.46)$ & $.19, p=.11$ \\
\hline $\begin{array}{l}\text { General sensitivity } \\
\text { at } 1 \text { year }\end{array}$ & $2.40(72), \mathrm{p}=.02 *$ & $7.08(1.25)$ & $6.21(1.05)$ & $.24, p=.04 *$ \\
\hline
\end{tabular}

Note: ${ }^{\mathrm{a}}$ Correlations are with length of breast-feeding. $* \mathrm{p}<.05$, two-tailed. 
Table 3

Correlations between mind-mindedness at 6 months with observed general sensitivity and observed feeding behaviors at 1 year

$\begin{array}{llll}\text { Mind- } & 1 & 2 & 3\end{array}$

mindedness

at 6 months

$\begin{array}{ll}\text { 1. Feeding } & .24_{\mathrm{a}}, \mathrm{p}=.04^{*} \\ \text { sensitivity } & .29_{\mathrm{b}}, \mathrm{p}=.01^{*}\end{array}$

2. Positive

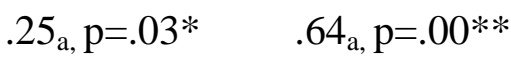

feeding

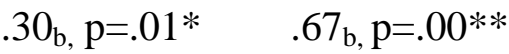

vocalization

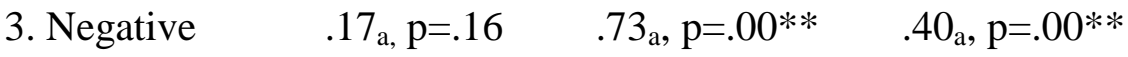

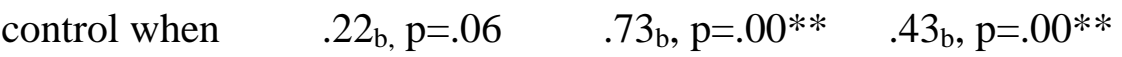

feeding

\begin{tabular}{|c|c|c|c|c|}
\hline 4. Sensitivity & $.30_{\mathrm{a}, \mathrm{p}} \mathrm{p}=.01 *$ & $.56_{\mathrm{a}, \mathrm{p}}=.00^{* *}$ & $.57_{\mathrm{a}, \mathrm{p}}=.00^{* *}$ & $.51_{\mathrm{a},} \mathrm{p}=.00 * *$ \\
\hline & $.36_{\mathrm{b}}, \mathrm{p}=.00 * *$ & $58 \mathrm{~b}, \mathrm{p}=.00 * *$ & $.59 \mathrm{~b}, \mathrm{p}=.00 * *$ & $.54 \mathrm{p} p$ \\
\hline
\end{tabular}

Note: a Partial correlations controlling for whether mother has breast-fed or not, and duration of breast-feeding in weeks; ${ }_{\mathbf{b}}$ Pearson's correlation coefficients. ${ }^{*} \mathrm{p}<.05, * * \mathrm{p}<.01$, twotailed. 